\title{
Treatment of livestock with systemic insecticides for control of Anopheles arabiensis in western Kenya
}

\author{
Richard M. Poché*, Dylan Burruss, Larisa Polyakova, David M. Poché and Rajesh B. Garlapati
}

\begin{abstract}
Background: Despite the implementation of vector control strategies, including insecticide-treated bed nets (ITN) and indoor residual spraying (IRS) in western Kenya, this area still experiences high level of malaria transmission. Novel vector control tools are required which target such vector species, such as Anopheles arabiensis, that feed outdoors and have minimal contact with ITNs and IRS.
\end{abstract}

Methods: To address this need, ivermectin, eprinomectin, and fipronil were evaluated in Zebu cattle under semi-field conditions to evaluate the potential of these compounds to reduce the survival of blood feeding An. arabiensis. Over the course of four experiments, lactating cattle received doses of oral ivermectin at $0.1 \mathrm{or} 0.2 \mathrm{mg} / \mathrm{kg}$, oral eprinomectin at 0.2 or $0.5 \mathrm{mg} / \mathrm{kg}$, topical eprinomectin at $0.5,0.75$, or $1.5 \mathrm{mg} / \mathrm{kg}$, or oral fipronil at $0.25,0.5,1.0$, or $1.5 \mathrm{mg} / \mathrm{kg}$. On days $1,3,5,7,14$, and 21 days post-treatment, cattle were exposed to An. arabiensis, and mosquito mortality postblood feeding was monitored. For the analysis of survival data, the Kaplan-Meier estimator and Mantel-Haenszel test was used to contrast the treatment and control survival functions.

Results: All three compounds significantly reduced the survival time of An. arabiensis. Twenty-one days posttreatment, mortality of mosquitoes fed on cattle dosed orally with 0.2 or $0.5 \mathrm{mg} / \mathrm{kg}$ eprinomectin, topically with eprinomectin at $0.5 \mathrm{mg} / \mathrm{kg}$, or orally with either 1.0 or $1.5 \mathrm{mg} / \mathrm{kg}$ fipronil was still significantly higher than control mortality.

Conclusions: These data demonstrate the effectiveness of three insecticidal compounds administered systemically to cattle for controlling the cattle-feeding mosquito An. arabiensis. Eprinomectin and fipronil provided the longestlasting control. Such endectocidal treatments in cattle are a promising new strategy for control of residual, outdoor malaria transmission and could effectively augment current interventions which target more endophilic vector species.

Keywords: Anopheles arabiensis, Ivermectin, Eprinomectin, Fipronil, Endectocide, Malaria, Cattle, Kenya

\section{Background}

While great strides are being made towards reducing the worldwide malaria burden, malaria still caused an estimated 584,000 deaths in 2013, mostly among African children [1]. In Kenya, there are an estimated 6.7 million new clinical cases and 4000 deaths each year, and those living in western Kenya have an especially high risk of malaria [2]. Malaria prevalence is highest in Kenya in the

\footnotetext{
*Correspondence: richard@genesislabs.com

Genesis Laboratories, P.O. Box 1195, Wellington, CO 80549, USA
}

lake endemic zone (38\%), is caused primarily by Plasmodium falciparum [3], and remains the most common cause of child morbidity in western Kenya [4]. In this region, $P$. falciparum is vectored by Anopheles gambiae sensu stricto (s.s.), An. arabiensis, and Anopheles funestus s.s. [5]. Given the behavioural diversity among these three vector species, a strategic investment must be made towards understanding their ecologies in order to design an effective, integrated management approach [6].

Anopheles gambiae s.s. and An. funestus s.s. are both highly anthropophilic, but $A n$. arabiensis feeds readily 
on non-human vertebrates, particularly cattle [7-9]. Anthropophily in An. arabiensis also varies significantly, ranging from a high preference for human blood in West Africa to almost exclusive zoophily in Madagascar [7, 1012]. In western Kenya, over half of the blood meals identified from An. arabiensis came from cattle, but a small proportion of An. gambiae s.s. also fed on cattle [13]. In areas where $A n$. arabiensis is more anthropophagic, blood feeding still occurs predominately outdoors [14]. These behaviour traits make $A n$. arabiensis less likely to encounter control strategies, which target endophagic and endophilic mosquitoes.

Zhou et al. [15] documented a resurgence of malaria parasite prevalence and malaria vectors in western Kenya despite increased usage of ITNs, which could be attributed to insecticide resistance and poor ITN coverage or usage. However, over the last 10 years, An. gambiae s.s. and $A n$. arabiensis have also undergone changes in their relative abundance, likely influenced by the implementation of IRS and ITNs $[13,16]$. While these strategies have led to the reduction of An. gambiae s.s. and An. funestus s.s., an unintentional consequence has been a proportionate increase in An. arabiensis [13]. Therefore, novel control strategies are needed for use in integrated malaria management programmes that target outdoor-feeding vectors not effectively controlled by ITNs and IRS.

One such approach is the use of "endectocides", or treatment of a vertebrate host with a systemic insecticide that haematophagous arthropod vectors would become exposed to upon blood feeding. This host-targeted insecticide strategy for vector control has already been demonstrated effective in reducing sand fly vectors of visceral and cutaneous leishmaniasis [17-20], and flea vectors of plague [21, 22]. Targeting cattle, a frequent blood host of An. arabiensis [7-9, 12, 13], with a systemic insecticide may be an efficient approach to control this vector species. Foy et al. [23] discussed the application and potential impact of ivermectin and other endectocides on malaria control. Community-directed ivermectin treatment of humans is already main strategy for control of onchocerciasis [24], and has been successfully used in humans for malaria control as well [23, 25]. Many studies have demonstrated the lethal effect of ivermectin on mosquitoes after imbibing ivermectin-treated blood [26-30]. Eprinomectin is commercially used for control of endoparasites of livestock [31] and was demonstrated to be as effective as ivermectin at killing blood-feeding An. gambiae s.s. in the laboratory [30]. However, further investigation is needed to determine whether efficacy against mosquitoes is maintained in an in vivo system, and ascertain the duration of effectiveness. Fipronil is a broad spectrum insecticide which blocks the GABAgated ion channels in the central nervous system [32].
Fipronil has been used to control ectoparasites on domestic animals [33], and as a pour-on or dip for cattle to control ticks [34, 35]. Mosquitoes are highly susceptible to fipronil during all life stages and by different routes of exposure [36-40]. However, field tests of fipronil as a systemic insecticide for mosquito control are currently lacking.

The long-term goal of the research is to create a product that can be utilized in an integrated malaria management programme, particularly to augment current control methodologies aimed at endophilic vectors by targeting more exophilic vectors with broader host utilization, such as $A n$. arabiensis. To that end, this study examined the efficacy of ivermectin, eprinomectin and fipronil on the survivorship of adult An. arabiensis. The specific aim of this study was to determine the percent mortality of adult female $A n$. arabiensis fed on cattle treated with different doses of ivermectin, eprinomectin, and fipronil, and determine the duration of this lethal effect post-treatment.

\section{Methods \\ Study area}

The study site was located $10 \mathrm{~km}$ west of Kisumu in the village of Kisian, Kenya (latitude $-0.073220^{\circ}$ and longitude $34.662974^{\circ}$ ).

\section{Cattle breed selection and cattle maintenance}

All animal activities were reviewed and approved by the Institutional Animal Care and Use committees at Genesis Laboratories, Inc. and the Kenya Medical Research Institute (KEMRI). Lactating Zebu cattle (Bos indicus) were leased or purchased from markets or from private individuals. Cattle were transported to the study cattle shed located on the grounds of US Centers for Disease Control and Prevention and the Kenya Medical Research Institute (KEMRI), Kisian, Kenya. Transportation permits were provided by the department of veterinary services nearest to each purchase location. Test subjects were housed in individual stalls $(1.5 \times 3 \mathrm{~m})$ within a covered cattle shed and were allowed periodic grazing in an outdoor pen during the 12-days acclimation period.

Upon arrival to the test facility each cow received an ear tag with a unique identification number and was inspected for general health. All test subjects were provided with clean tap water ad libitum and clean feed consisting of $8 \mathrm{~kg}$ of chopped Napier grass (Pennisetum purpureum) and $1.3 \mathrm{~kg}$ of dairy meal per day as directed by project veterinarians.

Cattle (test subjects) were maintained in a semi-controlled environment with adequate ventilation and natural light. Each test subject's general health, and the daily 
temperature and relative humidity of the animal facility were documented by staff during the acclimation period and the test.

\section{Treatment randomization}

A blocked randomization scheme by body weight was used to eliminate possible bias. Randomization was carried out using a random number generator service [41]. Each of the test subjects was assigned to either a control or treatment group. For each experiment, treatment groups which received doses of insecticide (test substance) consisted of three lactating Zebu cattle each, and the control group was allocated two lactating Zebu cattle. Precautions were taken to avoid animals contacting or grooming each other. The animals were housed individually in separate pens with a minimum distance to avoid contact between animals within and between treatment groups. Control animals were separated from the treatment animals.

\section{Administration of the test substance}

Four experiments were conducted in order to evaluate multiple doses each of ivermectin, fipronil, and eprinomectin (Table 1). Experiment 1, conducted from 20 Dec 2012-22 Jan 2013, consisted or dosing cattle orally with eprinomectin at doses of 0.2 or $0.5 \mathrm{mg} / \mathrm{kg}$, or topically with $0.5 \mathrm{mg} / \mathrm{kg}$ eprinomectin $\left(\right.$ Eprinex $\left.^{\circledR}\right)$. In experiment 2, conducted between 23 Jan 2013-26 Feb 2013, cattle were dosed orally with 0.1 or $0.2 \mathrm{mg} /$ $\mathrm{kg}$ ivermectin, or topically with $0.75 \mathrm{mg} / \mathrm{kg}$ eprinomectin. In experiment 3, conducted from 25 Apr 2013-6 Jun 2013 , cattle were dosed orally with either 1.0 or $1.5 \mathrm{mg} /$ $\mathrm{kg}$ fipronil, or topically with $1.5 \mathrm{mg} / \mathrm{kg}$ eprinomectin.
Experiment 4, conducted from 8 Aug 2013-22 Sept 2013, cattle received oral doses of fipronil at either 0.25 or $0.5 \mathrm{mg} / \mathrm{kg}$. For each of these experiments, cows were randomized into 3 cows per treatment group and 2 cows per control for a total of 11 cows per experiment. Test substance quantity was calculated using weights recorded no more than 3 days prior to dosing. Topical and oral application methods of administering eprinomectin were chosen to assess efficacy and explore differences between application routes on mosquito survivorship.

Experiment 1 Cattle in treatment group one (T1) received an eprinomectin dose of $0.2 \mathrm{mg} / \mathrm{kg}$ orally, subjects in T2 received $0.5 \mathrm{mg} / \mathrm{kg}$ orally and subjects in T3 received $0.5 \mathrm{mg} / \mathrm{kg}$ topically. Because eprinomectin is not commercially available in oral formulations, crystalline eprinomectin was weighed in the laboratory and placed in a capsule for oral application. For T3, eprinomectin was applied topically using liquid Eprinex@ (Merial Ltd., New Zealand) which was applied according to the manufacturer's application directions. The manufacturer recommended application for Eprinex@ pour-on commercial product is $1 \mathrm{ml} / 10 \mathrm{~kg}$ which would achieve a dosage of $0.5 \mathrm{mg}$ eprinomectin $/ \mathrm{kg}$ body weight.

Experiment 2 Treatment group T1 received a $0.1 \mathrm{mg} /$ $\mathrm{kg}$ ivermectin orally, subjects in T2 received $0.2 \mathrm{mg} / \mathrm{kg}$ ivermectin orally and subjects in T3 received $0.75 \mathrm{mg} /$ $\mathrm{kg}$ eprinomectin topically. Ivermectin was administered orally using boluses; ivermectin tablets were weighed in the laboratory and placed in a capsule for oral application. Eprinomectin was applied topically using liquid Eprinex $\odot$ applied according to the manufacturer's application directions, but with a higher dose.

Table 1 Listing of active ingredients, concentrations, route of administrations and total number of engorged mosquitoes used in the survival analysis per experiment

\begin{tabular}{|c|c|c|c|c|c|}
\hline Experiment & Treatment group & Active ingredient & Concentration & Route of administration & Mosquito sample size \\
\hline \multirow[t]{4}{*}{1} & T0 & Control & $\mathrm{n} / \mathrm{a}$ & $\mathrm{n} / \mathrm{a}$ & 379 \\
\hline & $\mathrm{T} 1$ & Eprinomectin & $0.2 \mathrm{mg} / \mathrm{kg}$ & Oral & 465 \\
\hline & $\mathrm{T} 2$ & Eprinomectin & $0.5 \mathrm{mg} / \mathrm{kg}$ & Oral & 396 \\
\hline & $\mathrm{T} 3$ & Eprinomectin & $0.5 \mathrm{mg} / \mathrm{kg}$ & Topical & 408 \\
\hline \multirow[t]{4}{*}{2} & TO & Control & $\mathrm{n} / \mathrm{a}$ & $\mathrm{n} / \mathrm{a}$ & 511 \\
\hline & $\mathrm{T} 1$ & Ivermectin & $0.1 \mathrm{mg} / \mathrm{kg}$ & Oral & 475 \\
\hline & $\mathrm{T} 2$ & Ivermectin & $0.2 \mathrm{mg} / \mathrm{kg}$ & Oral & 416 \\
\hline & $\mathrm{T} 3$ & Eprinomectin & $0.75 \mathrm{mg} / \mathrm{kg}$ & Topical & 522 \\
\hline \multirow[t]{4}{*}{3} & T0 & Control & $\mathrm{n} / \mathrm{a}$ & $\mathrm{n} / \mathrm{a}$ & 522 \\
\hline & $\mathrm{T} 1$ & Eprinomectin & $1.5 \mathrm{mg} / \mathrm{kg}$ & Topical & 537 \\
\hline & $\mathrm{T} 2$ & Fipronil & $1.0 \mathrm{mg} / \mathrm{kg}$ & Oral & 599 \\
\hline & $\mathrm{T} 3$ & Fipronil & $1.5 \mathrm{mg} / \mathrm{kg}$ & Oral & 575 \\
\hline \multirow[t]{3}{*}{4} & TO & Control & $\mathrm{n} / \mathrm{a}$ & $\mathrm{n} / \mathrm{a}$ & 460 \\
\hline & $\mathrm{T} 1$ & Fipronil & $0.5 \mathrm{mg} / \mathrm{kg}$ & Oral & 429 \\
\hline & $\mathrm{T} 2$ & Fipronil & $0.25 \mathrm{mg} / \mathrm{kg}$ & Oral & 407 \\
\hline
\end{tabular}


Experiment 3 Treatment group T1 received a $1.5 \mathrm{mg} / \mathrm{kg}$ eprinomectin topically, subjects in $\mathrm{T} 2$ received $1.0 \mathrm{mg} /$ $\mathrm{kg}$ fipronil orally and subjects in T3 received $1.5 \mathrm{mg} / \mathrm{kg}$ fipronil orally. Fipronil was administered orally using capsules. Technical grade fipronil was weighed in the laboratory and placed in a capsule for oral application. Eprinomectin was applied topically using liquid Eprinex@, applied as described above, but with a higher dose.

Experiment 4 Treatment group $\mathrm{T} 1$ received a fipronil dose of $0.5 \mathrm{mg} / \mathrm{kg}$ orally while subjects in T2 received $0.25 \mathrm{mg} / \mathrm{kg}$ orally. Fipronil was weighed in a laboratory and placed in a capsule for oral application. For each experiment, the control group (T0) was left untreated.

\section{Animal subject performance}

Clinical observations of test subjects were recorded daily by project staff during acclimation and experimentation phases of the study. In addition, a veterinarian conducted weekly health checks to more thoroughly examine test subject health. During application and experimentation periods, feed was weighed daily to assess the effects of test substances on the animals' appetite. When spillage occurred, feed was returned to the appropriate container and weighed to the nearest 0.5 gram. Cattle weights were recorded on the final day of acclimation and weekly throughout the course of the study. Differences in appetite and body mass were compared by evaluating test subject weight means and standard deviations before and after treatment.

\section{Mosquito bioassays}

All An. arabiensis used in this study were reared at the KEMRI/CDC, Kisian station, Kenya. Efficacy of each treatment was assessed by comparing survivorship of fully blood fed An. arabiensis at 1, 3, 5, 7, 14 and 21 days post treatment in experiments 1 and 2 . While in experiment 3 mosquitoes were exposed at days 1, 7, 10, 14 and 21 , in experiment 4 we exposed mosquitoes in days 1,3 , $5,7,14$ and 21 .

Prior to bioassays approximately $600 \mathrm{An}$. arabiensis adults were separated into an experimental cage and starved for $12 \mathrm{~h}$. The day of application, 11-12 plastic capsules were filled with approximately 50 3-4 day-old female mosquitoes. Containers were modified round paper cartons that were $9.5 \mathrm{~cm}$ deep and $8.5 \mathrm{~cm}$ in diameter, covered with nylon netting material on one end to facilitate blood feeding. Containers with mosquitoes were transported in a cooler to and from the cattle shed.

The day before application all cows had a circular patch approximately 6 inches in diameter shaved on the ventral portion of the abdomen to expose skin and facilitate feeding. One container with An. arabiensis was applied to the shaved location of each test subject and secured by wrapping an ace bandage around the torso. One test subject in the control group received one capsules to ensure that the number of cartons applied to each group was equal. Containers were attached to test subjects for $30 \mathrm{~min}$, and then carefully removed, and blood-fed females were counted. Unfed females were removed from the study.

Data were only analyzed for fully-engorged female mosquitoes. Blood fed females were placed into cages, provided with a $10 \%$ sugar source ad libitum. For each group of mosquitoes in experiment 1 and 2, mortality was monitored at 3, 6 and $24 \mathrm{~h}$ post feeding and then daily for approximately 12 days thereafter. In experiment 3 and 4 we followed the same scheme but mortality was recorded daily for 9 days after the first $24 \mathrm{~h}$.

\section{Statistical analysis}

The statistical analysis of the survival data obtained from the control and treatment groups was conducted using the "survival" package [42] for the software R [43]. The package implements the Kaplan-Meier estimator, which is used to calculate the survival function of a random variable in time. A survival curve is the plot of the survival function representing the survivorship of the target population. The statistical difference between the control and the treatment was assessed using the Mantel-Haenszel test as implemented in the survival package. Values smaller than 0.05 represent a significant difference between the control and treatment group. The resulting survival functions were used to estimate the median survival time and $95 \%$ confidence intervals for the estimate and the size of the effect of the active ingredient (Table 2).

To compare the effect of time on the effectiveness of the test substance we did a post hoc analysis for the same concentration and delivery method (a single row on a table). For this, the significant level was adjusted using a Bonferroni correction $(\alpha / \mathrm{n}$, where $\alpha$ is the significance level set at 0.05 and $n$ is the number of comparisons).

\section{Results}

\section{Cattle observations, health, and performance}

No adverse health effects arose in association with the treatments. For experiments 1-3, the test subject's mean daily feed consumption did not differ between the acclimation and test periods. For experiment 4, test subjects' mean daily feed consumption increased slightly from the acclimation ( $\mu=7.5 \mathrm{~kg}$ of hay/day, $\sigma=0.37)$ to the test period ( $\mu=7.8 \mathrm{~kg}$ of hay/day, $\sigma=0.02$ ); $t(15)=2.13$, $\mathrm{p}=0.049$. None of the cattle in any of the experiments experienced any large changes in their body mass over the course of the study. 


\section{Mosquito bioassays}

The data are presented in table form, with survival curves for all treatment groups and time points available in additional file 1 . Table 2 shows the median survival time (and $95 \%$ confidence intervals) with experiments separated by horizontal lines, each row correspond to a treatment (or control) in an experiment and each column is a time point when mosquitoes were challenged. Tables 3, 4, 5, 6 correspond to an experiment and each row shows the result for the active ingredient, concentration and delivery method. The columns represent the day post-exposure when mosquitoes were challenged against the test substance. The values shown are the $\mathrm{p}$ value of the comparison between a particular treatment and the control at a given day.

Experiment 1 Mortality of mosquitoes fed on cattle dosed orally with $0.2 \mathrm{mg} / \mathrm{kg}$ eprinomectin was delayed during the days immediately following treatment. Survivorship of mosquitoes in this group was not significantly different from the controls until 5 days post-treatment, but then remained significant out to 21 days post-treatment (Table 3) with the exception of day 7. In contrast, mortality of mosquitoes fed on cattle dosed orally or topically with $0.5 \mathrm{mg} / \mathrm{kg}$ eprinomectin was significantly different from controls by 1 day post-treatment (Table 3). The 7-day time point post-treatment was an anomaly, a control replicate had a large mortality by $24 \mathrm{~h}$.

Experiment 2 At the lowest dose of ivermectin, $0.1 \mathrm{mg} /$ $\mathrm{kg}$, mosquito survivorship was marginally significantly different from the control at 1 day post-treatment, but then not significant (Table 4). For mosquitoes fed on cattle dosed with $0.2 \mathrm{mg} / \mathrm{kg}$ ivermectin, survivorship was significantly different from the controls at 1,5 and 7 , but not at 3,14 and 21 days. For mosquitoes fed on cattle dosed topically with $0.75 \mathrm{mg} / \mathrm{kg}$ eprinomectin, survivorship was significantly different from the controls from 1 to 7 days, but not at 14 or 21 days (Table 4 ).

Experiment 3 For mosquitoes fed on cattle dosed topically with $1.5 \mathrm{mg} / \mathrm{kg}$ eprinomectin, survivorship was significantly different from the control out to 10 days, but not at 14 or 21 days (Table 5). For both doses of fipronil, mosquito survivorship was significantly different from the control at all time points out to 21 days (Table 5).

Table 2 Median survival time and $95 \%$ confidence interval per experiment

\begin{tabular}{|c|c|c|c|c|c|c|c|}
\hline Hours/experiment & $24 \mathrm{~h}(1 \mathrm{~d})$ & $72 \mathrm{~h}(3 \mathrm{~d})$ & $120 \mathrm{~h}(5 \mathrm{~d})$ & $168 \mathrm{~h}(7 \mathrm{~d})$ & $240 \mathrm{~h}(10 \mathrm{~d})$ & $336 \mathrm{~h}(14 \mathrm{~d})$ & $504 \mathrm{~h}(21 \mathrm{~d})$ \\
\hline Exp. 1 control & $216[168,264]$ & $144[96,192]$ & $168[144,192]$ & $96[48,216]$ & $\mathrm{n} / \mathrm{a}$ & $156[96,192]$ & $120[96,168]$ \\
\hline $0.2 \mathrm{mg} / \mathrm{Kg} \mathrm{OE}$ & $192[144,264]$ & $72[72,96]$ & $120[96,168]$ & $192[168,192]$ & $\mathrm{n} / \mathrm{a}$ & $24[24,96]$ & $96[96,120]$ \\
\hline $0.5 \mathrm{mg} / \mathrm{Kg} \mathrm{OE}$ & $24[24,24]$ & $48[48,72]$ & $72[72,96]$ & $168[120,216]$ & $\mathrm{n} / \mathrm{a}$ & $24[24,72]$ & $96[96,96]$ \\
\hline $0.5 \mathrm{mg} / \mathrm{Kg} \mathrm{TE}$ & $48[48,72]$ & $72[48,72]$ & $48[48,72]$ & $72[72,96]$ & $\mathrm{n} / \mathrm{a}$ & $48[48,72]$ & $96[96,120]$ \\
\hline Exp. 2 control & $144[120,168]$ & $72[48,120]$ & $216[168,288]$ & $240[216,264]$ & $\mathrm{n} / \mathrm{a}$ & $192[168,192]$ & $120[120,120]$ \\
\hline $0.1 \mathrm{mg} / \mathrm{Kg} \mathrm{Ol}$ & $96[72,96]$ & $48[48,72]$ & $132[48,264]$ & $144[96,240]$ & $\mathrm{n} / \mathrm{a}$ & $192[168,216]$ & $120[120,144]$ \\
\hline $0.2 \mathrm{mg} / \mathrm{Kg} \mathrm{Ol}$ & $72[72,72]$ & $60[48,72]$ & $72[72,120]$ & $144[96,168]$ & $\mathrm{n} / \mathrm{a}$ & $168[144,216]$ & $120[120,120]$ \\
\hline $0.75 \mathrm{mg} / \mathrm{Kg} \mathrm{TE}$ & $48[48,48]$ & $48[24,48]$ & $48[48,48]$ & $48[48,72]$ & $\mathrm{n} / \mathrm{a}$ & $168[144,192]$ & $120[120,120]$ \\
\hline Exp.3 control & $\mathrm{n} / \mathrm{a}^{1}[-\infty, \infty]$ & $\mathrm{n} / \mathrm{a}$ & $\mathrm{n} / \mathrm{a}$ & $216[216,240]$ & $168[144,168]$ & $192[192,240]$ & $\mathrm{n} / \mathrm{a}^{1}[240, \infty]$ \\
\hline $1.5 \mathrm{mg} / \mathrm{Kg} \mathrm{TE}$ & $24[24,24]$ & $\mathrm{n} / \mathrm{a}$ & $\mathrm{n} / \mathrm{a}$ & $48[24,48]$ & $72[48,96]$ & $192[192,240]$ & $\mathrm{n} / \mathrm{a}^{1}[216, \infty]$ \\
\hline $1.0 \mathrm{mg} / \mathrm{Kg}$ OF & $24[24,24]$ & $\mathrm{n} / \mathrm{a}$ & $\mathrm{n} / \mathrm{a}$ & $48[48,48]$ & $72[72,96]$ & $132[72,192]$ & $144[72,240]$ \\
\hline $1.5 \mathrm{mg} / \mathrm{Kg}$ OF & $24[24,24]$ & $\mathrm{n} / \mathrm{a}$ & $\mathrm{n} / \mathrm{a}$ & $24[24,48]$ & $48[24,48]$ & $84[48,144]$ & $72[48,168]$ \\
\hline Exp. 4 control & $144[120,144]$ & $168[168,216]$ & $\mathrm{n} / \mathrm{a}$ & $192[168,240]$ & $\mathrm{n} / \mathrm{a}$ & $\mathrm{n} / \mathrm{a}^{1}[216, \infty]$ & $240[216, \infty]$ \\
\hline $0.25 \mathrm{mg} / \mathrm{Kg}$ OF & $48[48,48]$ & $120[96,144]$ & $\mathrm{n} / \mathrm{a}$ & $48[48,48]$ & $\mathrm{n} / \mathrm{a}$ & $204[144, \infty]$ & $216[192, \infty]$ \\
\hline $0.5 \mathrm{mg} / \mathrm{Kg}$ OF & $48[48,72]$ & $120[120,144]$ & $\mathrm{n} / \mathrm{a}$ & $144[144,168]$ & $\mathrm{n} / \mathrm{a}$ & $216[144, \infty]$ & $\mathrm{n} / \mathrm{a}^{1}[216, \infty]$ \\
\hline
\end{tabular}

Values in square brackets represent the $95 \%$ confidence intervals for the estimated median lethal time; n/a, time point not tested; n/a ${ }^{1}$, denotes estimate nor applicable because the survival function did not reach 0.5 , therefore there is not a median value estimate; $\infty$, infinity, the survival function did not reach the corresponding to $95 \%$ limit value

$h$ hours, $d$ days, Exp. experiment, $O E$ oral eprinomectin, TE topical eprinomectin, Ol oral ivermectin, OF oral fipronil

Table 3 Kaplan-Meier curve comparisons (p values) for oral and topical doses of eprinomectin (experiment 1)

\begin{tabular}{llllll}
\hline Dose/days & $\mathbf{1}$ & $\mathbf{3}$ & $\mathbf{5}$ & $\mathbf{7}$ & $\mathbf{2 1}$ \\
\hline $0.2 \mathrm{mg} / \mathrm{Kg}$ oral & 0.92 & 0.23 & $5.7 \times 10^{-4 *}$ & 0.11 & $3.26 \times 10^{-4 *}$ \\
$0.5 \mathrm{mg} / \mathrm{Kg}$ oral & $2.37 \times 10^{-37 *}$ & $3.74 \times 10^{-4 *}$ & $2.3 \times 10^{-6 *}$ & 0.12 & $3.24 \times 10^{-4 *}$ \\
$0.5 \mathrm{mg} / \mathrm{Kg}$ pour on & $4.41 \times 10^{-7 *}$ & $8.82 \times 10^{-6 *}$ & $1.41 \times 10^{-7 *}$ & 0.148 & $0.09 \times 10^{-4 *}$ \\
\hline
\end{tabular}

* Comparison statistically different from the control at an adjusted $\alpha$ of 0.003 
Table 4 Kaplan-Meier curve comparisons (p values) for oral doses of ivermectin and topical eprinomectin (experiment 2)

\begin{tabular}{llllll}
\hline Dose/days & $\mathbf{1}$ & $\mathbf{3}$ & $\mathbf{5}$ & $\mathbf{7}$ & $\mathbf{2 1}$ \\
\hline $0.1 \mathrm{mg} / \mathrm{Kg}$ iver. & $0.0003^{*}$ & 0.098 & 0.199 & 0.017 & 0.082 \\
$0.2 \mathrm{mg} / \mathrm{Kg}$ iver. & $4.4 \times 10^{-16 *}$ & 0.004 & $0.0006^{*}$ & $3.77 \times 10^{-5 *}$ & 0.244 \\
$0.75 \mathrm{mg} / \mathrm{Kg}$ eprino. & $0.0^{*}$ & $3.1 \times 10^{-11 *}$ & $4.1 \times 10^{-10 *}$ & $0.0^{*}$ & 0.161 \\
\hline
\end{tabular}

* Comparison statistically different from the control at an adjusted $\alpha$ of 0.003

Experiment 4 For both doses of fipronil, mosquito survivorship was significantly different from the control out to 7 days (Table 6). Mosquito survivorship was not significantly different from the control for either dose at 14 and 21 days (Table 6).

\section{Discussion}

This study evaluated the endectocidal activity of three compounds in cattle against An. arabiensis mosquitoes in a semi-field environment. Positive results were achieved with each test substance, but with varying degrees of efficacy depending on dose and route of administration.

\section{Ivermectin}

Ivermectin mass drug administration (MDA) to humans for onchocerciasis control has been demonstrated to also reduce malaria parasite transmission by affecting mosquito survivorship, vector competence, re-feeding rates, and parity $[25,29,44,45]$. When administered to humans during MDA campaigns, the standard oral dose of ivermectin is $150 \mu \mathrm{g} / \mathrm{kg}$. While the aforementioned studies and others have well-characterized the use of ivermectin as a human endectocide for malaria vector control, this study was one of the first to evaluate the use of ivermectin in cattle for control of An. arabiensis.

Fritz et al. [26] evaluated a commercially-available injectable formulation of ivermectin in cattle, and found that most (90\%) of the An. gambiae s.s. that fed on the ivermectin-treated cattle within two weeks of treatment failed to survive more than 10 days post-blood meal. Further, no eggs were deposited by $A n$. gambiae s.s. that fed on ivermectin-treated cattle within 10 days of treatment [26]. These results are promising, however injectable formulations are difficult to administer and require veterinary expertise. In that light, the current study evaluated two oral doses of ivermectin. Of these oral formulations, the higher of the two doses $(0.2 \mathrm{mg}$ ivermectin/kg) achieved significant results out to 7 days (168 h) post-treatment. This result is also consistent with the described pharmacokinetics of this compound. Ivermectin has an elimination half-life of 32-178 h when administered intravenously, depending on species [46]. Day 3,
Table 5 Kaplan-Meier curve comparisons ( $p$ values) for oral doses of fipronil and topical eprinomectin (experiment 3)

\begin{tabular}{llllll}
\hline Dose/days & $\mathbf{1}$ & $\mathbf{7}$ & $\mathbf{1 0}$ & $\mathbf{1 4}$ & $\mathbf{2 1}$ \\
\hline $\begin{array}{c}1.5 \mathrm{mg} / \mathrm{Kg} \\
\mathrm{eprino} .\end{array}$ & $0.0^{*}$ & $0.0^{*}$ & $5.3 \times 10^{-11 *}$ & 0.734 & 0.351 \\
$\begin{array}{c}1.0 \mathrm{mg} / \mathrm{Kg} \\
\text { fipro. }\end{array}$ & $0.0^{*}$ & $0.0^{*}$ & $0.0^{*}$ & $0.006^{*}$ & $0.001^{*}$ \\
$\begin{array}{c}1.5 \mathrm{mg} / \mathrm{Kg} \\
\text { fipro. }\end{array}$ & $0.0^{*}$ & $0.0^{*}$ & $0.0^{*}$ & $8.32 \times 10^{-11 *}$ & $5.52 \times 10^{-12 *}$ \\
\hline
\end{tabular}

* Comparison statistically different from the control at an adjusted $\alpha$ of 0.003

Table 6 Kaplan-Meier curve comparisons ( $p$ values) for oral doses of fipronil (experiment 4)

\begin{tabular}{llllll}
\hline Dose/days & $\mathbf{1}$ & $\mathbf{3}$ & $\mathbf{7}$ & $\mathbf{1 4}$ & $\mathbf{2 1}$ \\
\hline $0.25 \mathrm{mg} / \mathrm{Kg}$ fipro. & $0.0^{*}$ & $5.0 \times 10^{-6 *}$ & $5.5 \times 10^{-14 *}$ & 0.10 & 0.768 \\
$0.5 \mathrm{mg} / \mathrm{Kg}$ fipro. & $0.0^{*}$ & $5.7 \times 10^{-8 *}$ & $6.8 \times 10^{-5 *}$ & 0.10 & 0.171 \\
\hline
\end{tabular}

* Comparison statistically different from the control at an adjusted $\alpha$ of 0.005

in the ivermectin experiment, had a control replicate with large mortality ( $38 \%$ ) by $24 \mathrm{~h}$. If the control replicate is removed, the median survival time in control is increased to $96 \mathrm{~h}$; $95 \%$ confidence interval [48, $120 \mathrm{~h}$ ] (Table 2). The $0.1 \mathrm{mg} / \mathrm{Kg}$ ivermectin treatment remains insignificant, while the $0.2 \mathrm{mg} / \mathrm{Kg}$ of ivermectin treatment becomes significant $(\mathrm{p}=0.001)$.

A significant effect on mosquito survivorship for approximately 1 week also corroborates the results obtained by Alout et al. [25], whereby a $33.9 \%$ reduction in survivorship of $A n$. gambiae s.s. was observed for 7 days following a MDA in humans. While this effect on mosquito survival was brief, a significant reduction in mosquito parity rates was observed for more than 2 weeks after the MDA [25]. Additionally, sporozoite rates were reduced by $77.5 \%$ for 15 days [25]. Kobylinski et al. [45] similarly also observed a $79 \%$ reduction in sporozoitepositive An. gambiae s.s. for over 2 weeks following MDA. Therefore, ivermectin treatments in cattle may similarly impact the vectorial capacity of $A n$. arabiensis in a field situation, and warrant further field investigation. 


\section{Eprinomectin}

Eprinomectin has established utility in the agricultural industry as an effective means to control endoparasite loads in cattle [31], with the additional health benefits of increasing cattle weight gain and milk production [31, 47]. However, eprinomectin has not been widely used for public health purposes. Butters et al. [30] evaluated eprinomectin alongside several other active ingredients in the laboratory for control of $A n$. gambiae s.s. and found it had a similar $\mathrm{LC}_{50}$ to ivermectin. Fritz et al. [48] also evaluated eprinomectin and ivermectin in the laboratory against $A n$. arabiensis and found both compounds to be effective at killing mosquitoes at concentrations under 10 parts per billion. However, no studies to date have evaluated eprinomectin under field conditions for control of anopheline malaria vectors.

In this study two oral $(0.2$ and $0.5 \mathrm{mg} / \mathrm{kg})$ and three topical $(0.5,0.75$, and $1.5 \mathrm{mg} / \mathrm{kg})$ doses of eprinomectin were evaluated. Of the oral formulations, the lower dose demonstrated a delayed effectiveness, with a significant effect on mosquito mortality at time points from 5 to 21 days post-treatment, but not at 7 days. In contrast, the $0.5 \mathrm{mg} /$ $\mathrm{kg}$ dose had a significant effect on mosquito mortality up to 5 days post-treatment and again at 21 days, but not at 7 or 14 days. Of the topical (pour-on) formulations, significant effects were observed immediately for all three doses (1 day post-treatment) (Tables 3, 4, 5), however, the lowest treatment $(0.5 \mathrm{mg} / \mathrm{kg})$ resulted in significant mosquito mortality for 21 days with the exception of day 7 (Table 3), however as previously mentioned, day 7 of experiment 1 had large mortality in a control replicate $(12 / 17$ dead by $24 \mathrm{~h})$. Removing this replicate increases the median survival time in the control from $96 \mathrm{~h}(95 \%$ confidence interval $48,116 \mathrm{~h}$ ) to $192 \mathrm{~h}$ ( $95 \%$ confidence interval 120, $264 \mathrm{~h}$ ). As a result the topical $0.5 \mathrm{mg} / \mathrm{kg}$ eprinomectin treatment becomes statistically significant $\left(\mathrm{p}=5.9 \times 10^{-4}\right)$.

For reasons unclear, the eprinomectin higher doses were effective for shorter periods of time (7 days for $0.75 \mathrm{mg} / \mathrm{kg}$ for and 10 days for $1.5 \mathrm{mg} / \mathrm{kg}$ ) than the lower doses (21 days for 0.5 and $0.2 \mathrm{mg} / \mathrm{Kg}$ ). The long-lasting low-dose effect of eprinomectin are unexpected and despite a large sample size (Table 1) and low variability (Table 2) further experimentation will be necessary to confirm these results. Oral formulations of eprinomectin are currently not commercially available, but should be further developed for study due to the potential for low concentrations to have a significant killing effect on mosquitoes (Table 3).

The same dose and route of administration was assessed for eprinomectin and ivermectin, although in separate experiments. When comparing $0.2 \mathrm{mg} / \mathrm{kg}$ oral ivermectin (Table 4) and $0.2 \mathrm{mg} / \mathrm{kg}$ oral eprinomectin
(Table 3), ivermectin was immediately effective with significant mosquito mortality out to 7 days post-treatment, whereas the effectiveness of eprinomectin was delayed, but lasted out to 21 days. Laboratory studies comparing eprinomectin and ivermectin have also demonstrated comparable effectiveness of both compounds but with slightly different pharmacokinetics. Butters et al. [30] reported significant knockdown of An. gambiae s.s. with both ivermectin and eprinomectin, however, the knockdown effect of eprinomectin was within the first hour following the blood meal whereas the knockdown effect for ivermectin was not apparent until $24 \mathrm{~h}$ after the blood meal [30]. The discrepancy between our results and those of Butters et al. [30] may relate to the difference in pharmacokinetics of these compounds under laboratory and in vivo conditions. In the laboratory where mosquitoes were exposed to blood spiked with the active ingredient, the results obtained would related directly to the activity of the compound itself in the absence of any metabolites or conditions associated with feeding on treated cattle. Ivermectin and eprinomectin have similar plasma kinetics and mean residence time (the amount of time one molecular stays in the organism) when administered to mice intravenously and orally, however with some variation in the rate and mechanism of drug elimination [49]. With the information available, it is also difficult to compare the concentration of active ingredient mosquitoes would have been exposed to at corresponding time points between these publications, or to know the relative contribution made by mosquito genetics, since Butters et al. [30] utilized An. gambiae s.s. G3 strain, and this study used $A n$. arabiensis sourced in Kenya. Further study is warranted to ascertain the nature of the delayed knockdown effect observed in An. arabiensis when exposed to eprinomectin circulating in cattle treated orally. More work is also needed to assess the complementary uses of these compounds in the field. Since eprinomectin is not approved for human use as is the case ivermectin, endectocidal treatments in cattle with eprinomectin may be a complementary approach to the use of ivermectin in people when both $A n$. gambiae s.s. and An. arabiensis are present.

\section{Fipronil}

Cattle were dosed orally with four different doses of fipronil over the course of two experiments. Fipronil dosing significantly reduced mosquito survivorship for at least 21 days when cattle were administered either 1.0 or $1.5 \mathrm{mg} / \mathrm{kg}$, and for at least 7 days at the lower doses of 0.25 and $0.5 \mathrm{mg} / \mathrm{kg}$. A significant effect may have occurred at the 14-day time point for the 0.25 and $0.5 \mathrm{mg} / \mathrm{kg}$ concentrations; however these data could not be analysed due to unexplained mortality in the control 
groups. Poché et al. [19] also tested fipronil as an endectocide in cattle, although for control of sand fly vectors of visceral leishmaniasis in India. In that study, four oral dose levels were evaluated: $0.5,1.0,2.0$, and $4.0 \mathrm{mg} / \mathrm{kg}$. Between $20 \%(0.5 \mathrm{mg} / \mathrm{kg})$ and $100 \%(4.0 \mathrm{mg} / \mathrm{kg})$ mortality was observed in adult Phlebotomus argentipes sand flies fed on treated cattle 21 days post-treatment with fipronil [19]. At the $1.0 \mathrm{mg} / \mathrm{kg}$ dose level in both studies, control of adult sand flies [19] and mosquitoes (this study) was significantly different from the controls at 21 days post treatment. This long-lasting efficacy makes fipronil a strong candidate for future malaria control field studies.

The use of fipronil as a public health endectocide has already been extensively evaluated for control of adult and larval sand fly vectors of leishmaniasis. In India, fipronil treatment of two rodent species resulted in $100 \%$ mortality of $P$. argentipes larvae following consumption of treated feces [18]. In that same study, $100 \%$ mortality of blood-feeding adult $P$. argentipes was also achieved when sand flies were allowed to feed on rodents up to 20 days post-treatment [18]. In Tunisia, Derbali et al. [20] reported that fipronil - treated baits consumed by the desert's jird (Meriones shawi) had a systemic effect on the survival of Phlebotomus papatasi after blood meal acquisition, as well as a feed-through effect on the survival of larval $P$. papatasi after consumption of feces. And as mentioned above, treatment of cattle with fipronil also successfully controlled adult and larval $P$. argentipes for 21 days [19]. Lopes et al. [35] also used fipronil treatment of cattle to control ivermectin-resistant cattle ticks, Rhipicephalus (Boophilus) microplus. The topically administered fipronil formulation $(1 \mathrm{mg} / \mathrm{kg})$ achieved efficacy values greater than $95 \%$ from 3 to 28 days after treatment. On 35, 42 and 49 days post-treatment, efficacy values were 94, 78 and $61 \%$, respectively [35]. The application of fipronil as a cattle endectocide for malaria control is a natural extension of these studies.

\section{Conclusions}

Ivermectin, eprinomectin, and fipronil each show promising potential as endectocides administered to cattle for lowering the survival rate of An. arabiensis mosquitoes, and hence reducing malaria transmission rates. Mosquito mortality was significantly higher than control mortality as long as 21 days post-treatment after mosquitoes fed on cattle dosed orally with 0.2 or $0.5 \mathrm{mg} / \mathrm{kg}$ eprinomectin, topically with eprinomectin at $0.5 \mathrm{mg} / \mathrm{kg}$, or orally with either 1.0 or $1.5 \mathrm{mg} / \mathrm{kg}$ fipronil. Other components of vectorial capacity were not evaluated, and would be valuable to incorporate into future studies. Endectocidal treatments in cattle are a promising new strategy for control of residual, outdoor malaria transmission driven by vectors that feed on cattle, and could effectively augment current interventions which target more endophilic vector species.

\section{Additional file}

Additional file 1. Survival curves for all treatment groups and time points.

\section{Authors' contributions}

The project was conceived and designed by RP. Principal Investigators were RP (Genesis) and NB (KEMRI). Project consultants were JG, and EW. The field work was conducted by RR, RG, DP, JK, DB, MNB. Chemical analyses were performed by LP. The data were analyzed and figures generated by SL. The manuscript was written by RCK with contributions by SL. All authors read and approved the final manuscript.

\section{Acknowledgements}

This project (KEMRI protocol \#2247) was approved by the KEMRI Scientific Steering committee, KEMRI Ethical Review Committee, and the KEMRI Animal Care and Use Committee, and the Genesis Laboratories Institutional Animal Care and Use Committee (protocols N12001 and N120018). This project was funded by the Bill and Melinda Gates Foundation, Global Health Grant Number OPP1032369. The following individuals provided valuable assistance in the field and consultation: Robyn R. Raban, Nabie Bayoh, Ned Walker, John Gimnig, Killion Ouko, Moses Ondanga, Bryant Mose, Alyssa Brayshaw, Diana Perry, Edward Esalimba, Caleb Odoyo, S. E. Otiang, and Jackie Kosgei.

\section{Compliance with ethical guidelines}

\section{Competing interests}

The authors declare that they have no competing interests.

Received: 29 June 2015 Accepted: 3 September 2015

Published online: 17 September 2015

\section{References}

1. WHO. Malaria. Fact sheet No. 94 (http://www.who.int/mediacentre/ factsheets/fs094/en/).

2. CDC —Malaria: Malaria Worldwide_CDC's Global Malaria ActivitiesKenya (http://www.cdc.gov/malaria/malaria_worldwide/cdc_activities/ kenya.html).

3. Division of Malaria Control (Ministry of Public Health and Sanitation): 2010 Kenya Malaria Indicator Survey. Malaria Indicator Survey. Nairobi, Kenya: DOMC, KNBS and ICF Macro; 2011.

4. Maina RN, Walsh D, Gaddy C, Hongo G, Waitumbi J, Otieno L, et al. Impact of Plasmodium falciparum infection on haematological parameters in children living in western Kenya. Malar J. 2010;9(Suppl 3):S4.

5. Okara RM, Sinka ME, Minakawa N, Mbogo CM, Hay SI, Snow RW. Distribution of the main malaria vectors in Kenya. Malar J. 2010;9:69.

6. Ferguson HM, Dornhaus A, Beeche A, Borgemeister C, Gottlieb M, Mulla MS, et al. Ecology: a prerequisite for malaria elimination and eradication. PLoS Med. 2010;7:e1000303.

7. Githeko A, Service M, Mbogo C, Atieli F, Juma F. Origin of blood meals in indoor and outdoor resting malaria vectors in western Kenya. Acta Trop. 1994;58:307-16

8. Costantini C, Sagnon N, della Torre A, Coluzzi M. Mosquito behavioural aspects of vector-human interactions in the Anopheles gambiae complex. Parassitologia. 1999;41:209-17.

9. Hadis M, Lulu M, Makonnen Y, Asfaw T. Host choice by indoorresting Anopheles arabiensis in Ethiopia. Trans R Soc Trop Med Hyg 1997:91:376-8. 
10. Garrett-Jones C, Boreham PFL, Pant CP. Feeding habits of anophelines (Diptera: Culicidae) in 1971-78, with reference to the human blood index: a review. Bull Entomol Res. 1980;70:165.

11. Bøgh C, Clarke SE, Pinder M, Sanyang F, Lindsay SW. Effect of passive zooprophylaxis on malaria transmission in the Gambia. J Med Entomol. 2001;38:822-8.

12. Duchemin JB, Tsy JM, Rabarison P, Roux J, Coluzzi M, Costantini C. Zoophily of Anopheles arabiensis and An. gambiae in Madagascar demonstrated by odour-baited entry traps. Med Vet Entomol. 2001;15:50-7.

13. Bayoh MN, Mathias DK, Odiere MR, Mutuku FM, Kamau L, et al. Anopheles gambiae: historical population decline associated with regional distribution of insecticide-treated bed nets in western Nyanza Province, Kenya. Malar J. 2010;9:62

14. Fornadel CM, Norris LC, Glass GE, Norris DE. Analysis of Anopheles arabiensis blood feeding behavior in Southern Zambia during the 2 years after introduction of insecticide-treated bed nets. Am J Trop Med Hyg. 2010:83:848-53.

15. Zhou G, Afrane YA, Vardo-Zalik AM, Atieli H, Zhong D, Wamae P, et al. Changing patterns of malaria epidemiology between 2002 and 2010 in western Kenya: the fall and rise of malaria. PLoS One. 2011;6:e20318.

16. Lindblade KA, Gimnig JE, Kamau L, Hawley WA, Odhiambo F, Olang G, et al. Impact of sustained use of insecticide-treated bednets on malaria vector species distribution and culicine mosquitoes. J Med Entomol. 2006:43:428-32

17. Wasserberg G, Poche R, Miller D, Chenault M, Zollner G, Rowton ED. Imidacloprid as a potential agent for the systemic control of sand flies. J Vector Ecol J Soc Vector Ecol. 2011;36(Suppl 1):S148-56

18. Ingenloff K, Garlapati R, Poche D, Singh MI, Remmers JL, Poche RM. Feed-through insecticides for the control of the sand fly Phlebotomus argentipes. Med Vet Entomol. 2013;27:10-8.

19. Poche RM, Garlapati R, Singh MI, Poche DM. Evaluation of fipronil oral dosing to cattle for control of adult and larval sand flies under controlled conditions. J Med Entomol. 2013:50:833-7.

20. Derbali M, Polyakova L, Boujaama A, Burruss D, Cherni S, Barhoumi W, et al. Laboratory and field evaluation of rodent bait treated with fipronil for feed through and systemic control of Phlebotomus papatasi. Acta Trop. 2014;135:27-32

21. Borchert JN, Davis RM, Poche RM. Field efficacy of rodent bait containing the systemic insecticide imidacloprid against the fleas of California ground squirrels. J Vector Ecol J Soc Vector Ecol. 2009;34:92-8.

22. Borchert JN, Poché RM. Pest control methods. 2011. US Patent and Trademark Office. US7943160 B2. Washington, D.C., filed October 25, 2005, and issued May 17, 2011. (http://assignment.uspto.gov/\#/ search?q=7943160).

23. Foy BD, Kobylinski KC, da Silva IM, Rasgon JL, Sylla M. Endectocides for malaria control. Trends Parasitol. 2011:27:423-8.

24. Noma M, Zoure HGM, Tekle AH, Enyong PAl, Nwoke BEB, Remme JHF. The geographic distribution of onchocerciasis in the 20 participating countries of the African Programme for Onchocerciasis Control: (1) priority areas for ivermectin treatment. Parasit Vectors. 2014;7:325.

25. Alout H, Krajacich BJ, Meyers JI, Grubaugh ND, Brackney DE, Kobylinski $\mathrm{KC}$, et al. Evaluation of ivermectin mass drug administration for malaria transmission control across different West African environments. Malar J. 2014;13:417.

26. Fritz ML, Siegert PY, Walker ED, Bayoh MN, Vulule JR, Miller JR. Toxicity of bloodmeals from ivermectin-treated cattle to Anopheles gambiae s.l. Ann Trop Med Parasitol. 2009;103:539-47.

27. Tesh RB, Guzman H. Mortality and infertility in adult mosquitoes after the ingestion of blood containing ivermectin. Am J Trop Med Hyg. 1990:43:229-33.

28. Bockarie MJ, Hii JL, Alexander ND, Bockarie F, Dagoro H, Kazura JW, et al. Mass treatment with ivermectin for filariasis control in Papua New Guinea: impact on mosquito survival. Med Vet Entomol. 1999;13:120-3.

29. Kobylinski KC, Deus KM, Butters MP, Hongyu T, Gray M, da Silva IM, et al. The effect of oral anthelmintics on the survivorship and re-feeding frequency of anthropophilic mosquito disease vectors. Acta Trop. 2010;116:119-26.

30. Butters MP, Kobylinski KC, Deus KM, da Silva IM, Gray M, Sylla M, Foy BD. Comparative evaluation of systemic drugs for their effects against Anopheles gambiae. Acta Trop. 2012;121:34-43.

31. Kunkle BN, Williams JC, Johnson EG, Stromberg BE, Yazwinski TA, Smith $L L$, et al. Persistent efficacy and production benefits following use of extended-release injectable eprinomectin in grazing beef cattle under field conditions. Vet Parasitol. 2013;192:332-7.

32. Jackson D, Cornell CB, Luukinen B, Buhl K, Stone D. Fipronil Technical Fact Sheet. National Pesticide Information Center, Oregon State University Extension Services. 2009. (http://npic.orst.edu/factsheets/fiptech.pdf).

33. Hutchinson MJ, Jacobs DE, Fox MT, Jeannin P, Postal JM. Evaluation of flea control strategies using fipronil on cats in a controlled simulated home environment. Vet Rec. 1998;142:356-7.

34. Davey RB, Ahrens EH, George JE, Hunter JS 3rd, Jeannin P. Therapeutic and persistent efficacy of fipronil against Boophilus microplus (Acari: |xodidae) on cattle. Vet Parasitol. 1998:74:261-76.

35. Lopes WDZ, Cruz BC, Teixeira WFP, Felippelli G, Maciel WG, Buzzulini C, et al. Efficacy of fipronil (1.0 mg/kg) against Rhipicephalus (Boophilus) microplus strains resistant to ivermectin $(0.63 \mathrm{mg} / \mathrm{kg})$. Prev Vet Med. 2014;115:88-93

36. Ali A, Nayar JK, Gu WD. Toxicity of a phenyl pyrazole insecticide, fipronil, to mosquito and chironomid midge larvae in the laboratory. J Am Mosa Control Assoc. 1998;14:216-8.

37. Dennett JA, Bernhardt JL, Meisch MV. Operational note effects of fipronil and lambda-cyhalothrin against larval Anopheles quadrimaculatus and nontarget aquatic mosquito predators in Arkansas small rice plots. J Am Mosq Control Assoc. 2003;19:172-4.

38. Xue R-D. Toxicity of permethrin-, malathion-, and fipronil-treated plant foliage to Aedes albopictus and Aedes aegypti. J Am Mosq Control Assoc. 2008;24:169-71.

39. Xue R-D, Pridgeon JW, Becnel JJ, Ali A. Fipronil as a larvicide against the container-inhabiting mosquito, Aedes albopictus. J Am Mosq Control Assoc. 2009:25:224-7.

40. Allan SA. Susceptibility of adult mosquitoes to insecticides in aqueous sucrose baits. J Vector Ecol J Soc Vector Ecol. 2011;36:59-67.

41. True Random Number Service (https://www.random.org/).

42. Therneau TM. A Package for Survival Analysis in S. 2015.

43. R Core Team. R: a language and environment for statistical computing. Vienna: R Foundation for Statistical Computing; 2014.

44. Sylla M, Kobylinski KC, Gray M, Chapman PL, Sarr MD, Rasgon JL, Foy BD. Mass drug administration of ivermectin in south-eastern Senegal reduces the survivorship of wild-caught, blood fed malaria vectors. Malar J. 2010;9:365.

45. Kobylinski KC, Sylla M, Chapman PL, Sarr MD, Foy BD. Ivermectin mass drug administration to humans disrupts malaria parasite transmission in Senegalese villages. Am J Trop Med Hyg. 2011;85:3-5

46. Pharmacokinetics of Anthelmintics (http://www.merckvetmanual.com/ $\mathrm{mvm} /$ pharmacology/anthelmintics/pharmacokinetics_of_anthelmintics. html).

47. Verschave SH, Vercruysse J, Forbes A, Opsomer G, Hostens M, Duchateau $\mathrm{L}$, et al. Non-invasive indicators associated with the milk yield response after anthelmintic treatment at calving in dairy cows. BMC Vet Res. 2014;10:264.

48. Fritz ML, Walker ED, Miller JR. Lethal and sublethal effects of avermectin/ milbemycin parasiticides on the African malaria vector, Anopheles arabiensis. J Med Entomol. 2012:49:326-31.

49. Kiki-Mvouaka S, Menez C, Borin C, Lyazrhi F, Foucaud-Vignault M, Dupuy J, et al. Role of P-glycoprotein in the disposition of macrocyclic lactones: a comparison between ivermectin, eprinomectin, and moxidectin in mice. Drug Metab Dispos. 2010;38:573-80. 